\title{
Carpal tunnel syndrome in patients on intermittent haemodialysis
}

\author{
D. J. WARREN \\ M.R.C.P. \\ L. S. OTIENO* \\ M.R.C.P. \\ Medical Renal Unit, Department of Medicine, Royal Infirmary, Edinburgh EH3 9YW
}

\begin{abstract}
Summary
Twenty-three out of thirty-six patients using a forearm arteriovenous fistula for dialysis reported symptoms of carpal tunnel syndrome in the fistula hand during dialysis. By contrast with other reported groups of patients with the syndrome, symptoms were common in male patients, and confined to the non-dominant (fistula) hand. Predialysis venous pressure in the hand and hand volume were increased on the side of the fistula, and increasing hand volume during dialysis was associated with the development of symptoms of carpal tunnel syndrome. Severe symptoms during dialysis necessitated carpal tunnel decompression in two male patients. Measures to reduce the incidence of this complication of arteriovenous fistulae in dialysis patients are discussed.
\end{abstract}

\section{Introduction}

The carpal tunnel syndrome is a common cause of neurological symptoms in the hand, and occurs most frequently in the dominant hand of a middleaged woman (Phalen, 1972; Leading article, 1974; Phalen, 1970). We report here the occurrence of this syndrome in the non-dominant hand in a large proportion of a predominantly male haemodialysis population, and have measured hand volumes and venous pressure in the hand in an attempt to understand the mechanism of its development.

\section{Methods}

A questionnaire was sent to thirty-eight home and hospital patients who were using a forearm fistula for regular haemodialysis. Patients were asked about pain, swelling and abnormalities in sensation in their hands, and to specify the fingers involved. The relationship of the symptoms to dialysis, and details of methods used to relieve any symptoms were also requested.

Hand volume was measured by water displacement, as described by Bhatia, Hadden and Montgomery (1969). In twenty-eight dialysis patients hand volume was measured immediately before dialysis,

* British Council Scholar; seconded from Kenyatta National Hospital, P.O. Box 30024, Nairobi, Kenya.

Currespondence: Dr D. J. Warren, Department of Medicine, Royal Infirmary, Edinburgh EH3 9YW. and in six patients immediately after removing the cannulae post dialysis. Patients were matched for age and build with asymptomatic controls within the hospital.

Venous pressure in the dorsum of the hand was measured in thirty patients using a central venous pressure manometer set filled with heparinized saline and connected to a 19-gauge needle. The patient was seated and the hands placed prone on a flat surface at such a height that pressure in the veins of the dorsum of the non-fistula hand was zero. The pressure in the fistula hand was then recorded in $\mathrm{cmH}_{2} \mathrm{O}$.

All results are expressed as the mean \pm the standard deviation from the mean.

\section{Results \\ Questionnaire response}

Completed questionnaires were returned by thirty-six patients, twenty-seven male and nine female. The mean age of this group was $40 \cdot 8 \pm 6 \cdot 3$ years, and the mean duration of chronic dialysis $1.8 \pm 1.3$ years. Arteriovenous fistulae were present in the non-dominant hand in thirty-two patients. Twenty-three patients (seventeen male, six female) reported symptoms in the fistula hand on dialysis as follows: pain eleven $(31 \%)$, swelling nine $(25 \%)$, numbness or paraesthesiae twenty-two $(61 \%)$. On subsequent detailed questioning the patients reporting paraesthesiae or pain localized the symptoms to some or all of the first four digits and none developed pain or paraesthesiae in the fifth digit. No symptoms in either hand were reported by eleven patients, and two patients described an aching pain in both hands on dialysis.

Of the twenty-three patients who described symptoms on dialysis, all reported relief from pain, numbness or paraesthesiae following the activity required to strip and clean their machines post dialysis. Relief of swelling post dialysis was partial in five, and complete in four patients. Swelling of the fistula hand during non-dialysis nights was reported by six of the nine patients who also reported this symptom on dialysis. Swelling of the hand on non-dialysis nights resolved spontaneously on resumption of normal activity the following day. 


\section{Physical examination}

Oedema of the fistula hand post dialysis was readily detected in all patients who reported swelling of the hand in reply to the questionnaire. In addition, persistent gross oedema of the fistula hand was present between dialyses in five patients, and two of them reported persistent paraesthesiae and numbness between dialyses.

In four of the twenty-three patients who reported neurological symptoms, diminution of sensation to light touch was detected in the distribution of the median nerve immediately post dialysis, but was undetectable $24 \mathrm{hr}$ later. Atrophy of the muscles of the thenar eminence was not detected in any patient, but minor degrees of wasting could not have been detected in patients with oedema of the hand.

\section{Hand volume studies}

These were performed on twenty-three male and five female right-handed symptomatic patients and in matched controls and the results are shown in the table. In the control subjects the volume of the dominant hand was greater in both males $(5 \cdot 1 \%$; $P>0.10)$ and females $(5.7 \% ; P>0 \cdot 10)$. By contrast, the non-dominant (fistula) hand was larger in male $(18 \% ; P<0.001)$ and female $(21 \% ; P<0.01)$ dialysis patients.

TABLE 1. Hand volumes ( $\mathrm{ml})$. The differences between hand volumes are expressed as a percentage of the volume of the smaller hand, and the range of difference is shown in brackets

\begin{tabular}{cccc}
\hline & $\begin{array}{c}\text { Dominant } \\
\text { hand }\end{array}$ & $\begin{array}{c}\text { Non-dominant } \\
\text { hand }\end{array}$ & $\begin{array}{c}\text { Difference } \\
(\%)\end{array}$ \\
\hline $\begin{array}{c}\text { Controls } \\
\text { Male }\end{array}$ & $408 \pm 51$ & $388 \pm 49$ & $\begin{array}{c}5 \cdot 1 \pm 3 \\
(0-13)\end{array}$ \\
Female & $238 \pm 24$ & $225 \pm 31$ & $\begin{array}{c}5 \cdot 7 \pm 2 \\
(5-9)\end{array}$ \\
Patients & $384 \pm 53$ & $452 \pm 66$ & $\begin{array}{c}18 \pm 4 \\
(10-27)\end{array}$ \\
Male & $244 \pm 48$ & $296 \pm 51$ & $\begin{array}{c}21 \pm 3 \\
(10-28)\end{array}$ \\
Female & & & \\
\hline
\end{tabular}

In six patients who developed symptoms on dialysis, hand volumes were measured pre- and postdialysis. During 8-10 hr of nocturnal haemodialysis, the volume of the non-fistula hand increased by $4 \%$ $(P>0 \cdot 10)$, and that of the fistula hand by $15 \%$ $(P<0.05)$.

\section{Venous pressure studies}

Predialysis comparison of venous pressure measurements in the dorsum of the hand in thirteen symptomatic patients showed that pressure in the fistula hand was $21 \pm 4 \mathrm{cmH}_{2} \mathrm{O}$ higher than in the non-fistula hand $(P<0.001)$.

\section{Discussion}

Mechanism of median nerve compression in dialysis patients

A minority of patients with the carpal tunnel syndrome have readily identifiable causes of median nerve compression, such as osteophytes, rheumatoid granulation tissue and benign tumours. No such cause is found in the majority of patients, and the syndrome is frequently attributed to oedema, particularly in conditions such as pregnancy and myxoedema. No hand volume measurements appear to have been made to support this hypothesis.

In the present study twenty-three out of thirty-six dialysis patients reported symptoms of carpal tunnel syndrome in the non-dominant (fistula) hand. The diagnosis was made on the history alone in almost all patients, and other investigators have also found that sensory loss may be difficult to demonstrate in early cases, or where there is marked skin thickening (Leading Article, 1974). We found that in our dialysis patients the normal difference between the volumes of the dominant and non-dominant hands is reversed, so that the volume of the non-dominant hand is greater than that of the dominant hand, and associated with a significant elevation of venous pressure in that hand. In addition the development of symptoms in the fistula hand during nocturnal haemodialysis is associated with a much greater increase in hand volume than occurs in the contralateral hand. We propose that the increased venous pressure in the hand which follows construction of an arteriovenous fistula is the primary cause of oedema. The normal peripheral vasodilatation which occurs at night is responsible for further increase in hand volume, and exacerbated by the relative immobility of the fistula arm and hand during haemodialysis. The importance of immobility of the dialysis hand in the development of symptoms is supported by the evidence from many patients that symptoms disappear rapidly during the activity required to strip their machines post dialysis.

In two male patients severe pain in the fistula hand made self-dialysis impossible. Surgical decompression of the carpal tunnel resulted in prompt relief of these symptoms, and the patients are now established on home dialysis, although marked oedema of the hand persists in both.

\section{Prevention and treatment of carpal tunnel syndrome in dialysis patients}

We suggest that high venous pressure in the hand is the primary physiological abnormality leading to symptoms of median nerve compression in the carpal tunnel in dialysis patients. Arteriovenous fistulae for 
dialysis are usually constructed by a side-to-side anastomosis between the radial artery and a superficial vein. Although this technique may result in suitable cannulation sites distal to the fistula, it is also likely to result in high venous pressure in the hand and to be one factor leading to symptoms of carpal tunnel syndrome. Construction of an end-toside rather than a side-to-side anastomosis of the vein to the radial artery may be less likely to result in transmission of the high pressure from the venous side of the fistula to hand veins.

Most symptomatic patients achieve some relief from symptoms by movement of the fistula hand during dialysis, but pain which limits a patient's competence in self-dialysis is an indication for carpal tunnel decompression.

\section{References}

Bhatia, S.K., Hadden, D.R. \& Montgomery, D.A. (1969) Hand volume and skin thickness in a normal population and in acromegaly. Acta endocrinologica, 61, 385.

Leading ArTicle (1974) Tunnel tactics. British Medical Journal, ii, 573.

Phalen, G.S. (1970) Reflections on 21 years experience with the carpal-tunnel syndrome. Journal of the American Medical Association, 212, 1365.

Phalen, G.S. (1972) The Carpal-tunnel syndrome. Clinical Orthopaedics, 83, 29. 